\title{
Severe accordion effect: Myocardial ischemia due to wire complication during percutaneous coronary intervention: A case report
}

\author{
Gerasimos Gavrielatos*1, Loukas K Pappas ${ }^{1}$, Prodromos Anthopoulos², \\ Anastasios Salachas ${ }^{2}$, Georgios Ifantis ${ }^{2}$ and Ioannis Antonellis ${ }^{2}$
}

\author{
Address: ${ }^{12 n d}$ Department of Cardiology, Evangelismos General Hospital, Athens, Greece and ${ }^{2}$ Cardiac Catheterization and Interventional \\ Cardiology Department, Evangelismos General Hospital, Athens, Greece \\ Email: Gerasimos Gavrielatos* - makisgab@yahoo.gr; Loukas K Pappas - drluke@hol.gr; Prodromos Anthopoulos - prodromos_a@yahoo.com; \\ Anastasios Salachas - makisgab@hotmail.com; Georgios Ifantis - stayraitos@panafonet.gr; Ioannis Antonellis - sofiannato@yahoo.gr \\ * Corresponding author
}

Published: 2 September 2008

Cases Journal 2008, I:138 doi:10.1 186/1757-1626-1-138

This article is available from: http://www.casesjournal.com/content/l/I//38

(C) 2008 Gavrielatos et al; licensee BioMed Central Ltd.

This is an Open Access article distributed under the terms of the Creative Commons Attribution License (http://creativecommons.org/licenses/by/2.0), which permits unrestricted use, distribution, and reproduction in any medium, provided the original work is properly cited.
Received: 4 July 2008

Accepted: 2 September 2008

\begin{abstract}
A mechanical alteration during manoeuvring of stiff guidewires in tortuous coronary arteries frequently induces vessel wall shortening and coronary psedostenosis, referred as accordion phenomenon. Subtraction of the guidewires normally leads to the entire resolution of the lesions. A case of this transient angiographic finding, during percutaneous coronary intervention in a tortuous right coronary artery, which resulted in a flow limiting effect and myocardial ischemia, is described in the present report. Differential diagnosis from potential procedure complications and interventional methodology issues are discussed, while similar reports are reviewed.
\end{abstract}

\section{Introduction}

Accordion phenomenon is a transient angiographic defect observed during the course of percutaneous coronary intervention (PCI) in tortuous vessels. Herein is described a case of accordion effect in right coronary artery accompanied by ischemic electrocardiographic alterations and severe chest pain. Current interventional practise and technical details are being discussed.

\section{Case presentation}

A 60-year-old female with a history of hypertension and dyslipidemia visited the emergency department due to recurrent episodes of progressive, effort-related angina for the past two months. Physical examination revealed a mild systolic murmur best heart at the apex and her blood pressure was 150/85 mm Hg. Electrocardiogram (ECG) showed T wave inversion in leads I, AVL, V4-V6. The lev- els of cardiac enzymes were between normal ranges. Twodimensional echocardiography showed hypokinesis of the inferoposterior and lateral wall with ejection fraction of $50 \%$ and mitral regurgitation (grade I/IV). The patient was admitted in hospital and treated with aspirin $325 \mathrm{mg}$, oral nitrates and clopidogrel $75 \mathrm{mg} \times 1$.

A non-elective diagnostic coronary angiogram (CAG) was performed with standard $6 \mathrm{~F} 4$ Judkins (Cordis, Johnson\&Johnson, Miami, FL, USA) catheters via a right femoral approach. Contrast injection revealed two stenotic lesions of $70 \%$ and $80 \%$, at the proximal and middle segment respectively, of a right coronary artery (RCA), with significant tortuosity (Figure 1a). Coronary angioplasty of the right coronary artery was decided. After an unsuccessful attempt with a 0.014-inch Hi-torque Extra Suport (Guidant Corporation; Santa Clara, USA) guidewire to 

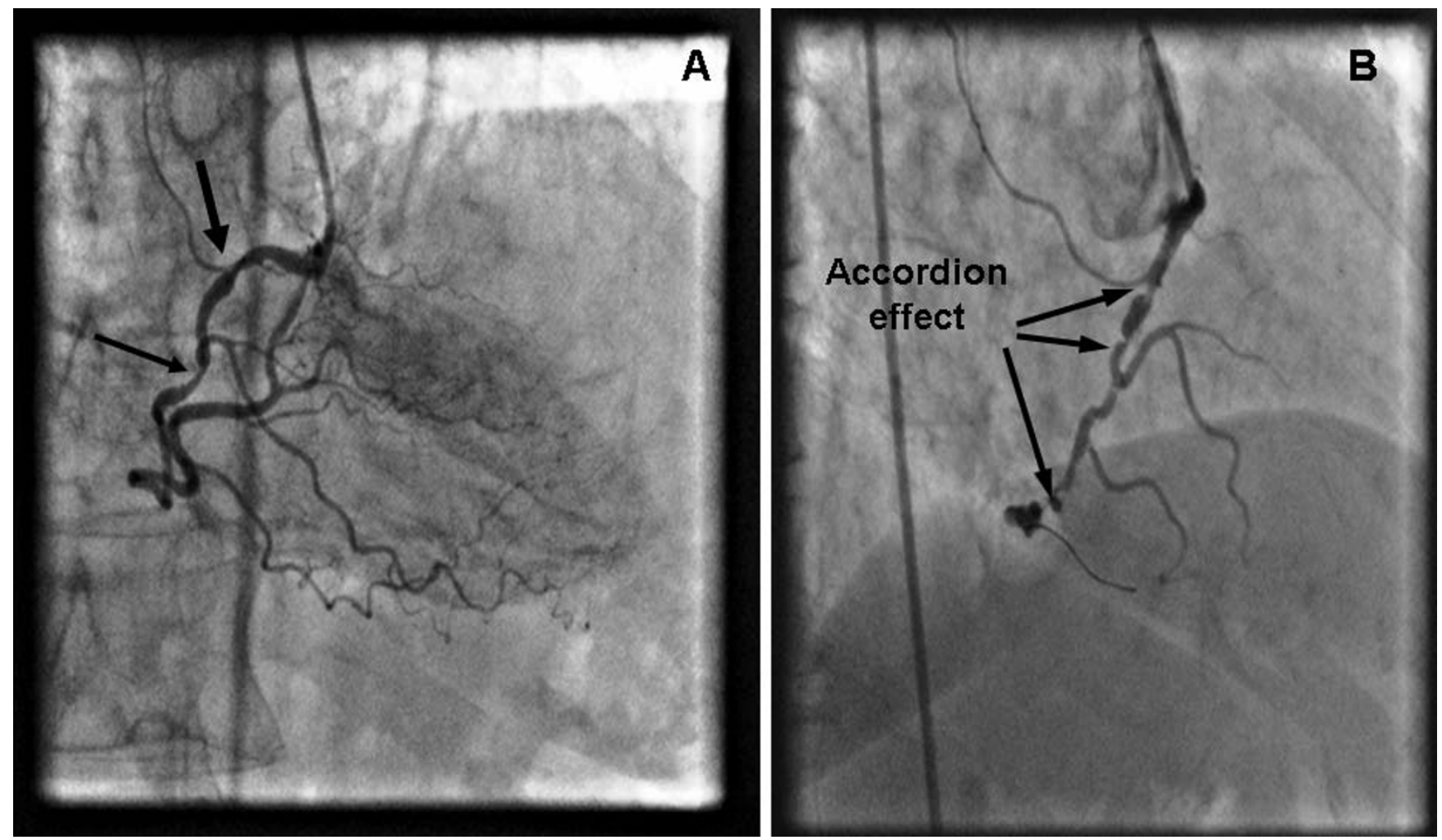

Figure I

(a) Coronary angiography of the right coronary artery in the AP-cranial projection demonstrating two stenotic lesions of $\mathbf{7 0 \%}$ and $\mathbf{8 0} \%$ (arrows), located at the proximal and middle segment respectively, of a right coronary artery (RCA), with significant tortuosity. (b) Several slit-like stenotic lesions resembling accordion effect developed after successful wiring using a 0.0I4-inch Hi-torque Cross-IT guide-wire and balloon dilatation at the straightened segments (arrows). Multiple intracoronary administrations of nitrate did not resolve the newly appeared lesions.

cross the lesions, a 0.014-inch Hi-torque Cross-IT (Guidant Corporation; Santa Clara, CA, USA), intermediate guidewire was advanced across the stenoses and balloon dilatation was performed with a $2 \times 10 \mathrm{~mm}$ balloon (Flash, Bolton Medical, USA) at 12 atm. The tortuous proximal segments were completely straightened by this technique and after the balloon was removed, angiographic control exposed slit like multiple filling defects along the longitudinal axis of the RCA, an appearance of stenoses strongly suggesting the accordion effect or dissection, and vasospasm (Figure 1b). Isosorbide dinitrate was administrated intracoronary in order to clarify the possibility of coronary spasm but the angiographic appearance of the RCA did not change. The patient had severe chest pain with ECG changes (ST elevation on leads II, III, aVF) and a drop of blood pressure at critical levels (90/60 $\mathrm{mmHg})$. As the deformity of the artery persisted and in view of patient's symptoms stenting was performed. A $2.75 \mathrm{~mm} \times 14 \mathrm{~mm}$ stent (Apollo Cordynamic, Bionert, Barcelona, Spain) was delivered with little resistance at the middle segment lesion expanded at 16 atm. A second $3 \mathrm{~mm} \times 14 \mathrm{~mm}$ stent (Apollo, Cordynamic, Bionert, Bar- celona, Spain) was deployed at the proximal lesion which was expanded at 18 Atm (Figure $2 \mathrm{a}$ and $2 \mathrm{~b}$ ). Angiography following stenting showed residual stenosis at the edges of both stents (Figure 2c). Although coronary spasm was highly suspected, several intracoronary administrations of isosorbide dinitrate could not relieve of this narrowing. The appearance of newly developed lesion was thought as a repeated accordion phenomenon. Thus, the guidewire was withdrawn and this resulted in resolution of the new stenosis and resumption of previous proximal tortuosity of the artery (Figure 3). The final outcome was excellent. The patient had an uneventful recovery and was discharged after 24 hours.

\section{Discussion}

Appearance of the accordion phenomenon, during routine angioplasty procedure, is not uncommon and is produced by mechanical alteration of the geometry and the curvature of the vessel due to straightening effect and shortening of the artery, preceded from guidewire or catheter balloon manipulation [1]. The highest incidence of accordion effect is seen when highly tortuous arterial ves- 


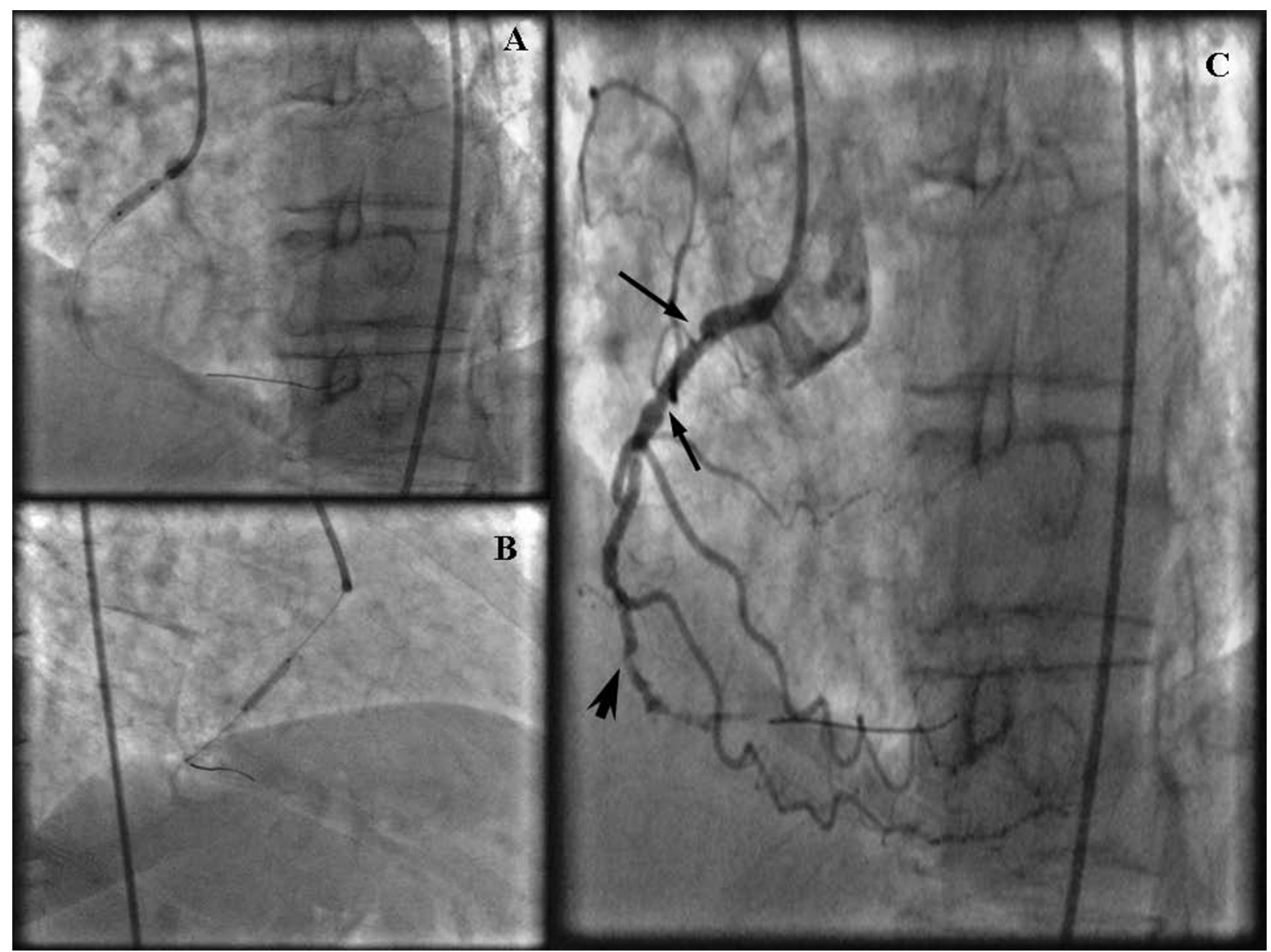

\section{Figure 2}

$(a, b)$ Stent deployment at the middle and proximal segment lesions due to persistent ST-segment elevation with hemodynamic instability.(c) New stenosis at the proximal and distal edge of the proximal stent (arrows) and the distal edge of the peripheral lesion delivered stent (arrowhead). Despite intracoronary injection of isosorbide dinitrate the residual stenoses still remained, indicating a repeated accordion phenomenon.

sels are linearized with a stiff guidewire and it can be simply be reversed by the withdrawn of the mechanical device causing the artery deformation [2].

The accordion phenomenon has been primarily reported in the era of PCI $[1,3]$. The right coronary artery is thought to be predominantly prone to this phenomenon because the artery is entrenched in the epicardial fat tissue and courses rather freely in the atrioventricular groove. It has also been rarely described in the internal mammary artery [4], the left main coronary artery [1], during percutaneous transluminal angioplasty of the iliac artery [5] and through carotid stenting [2].

A stiff guidewire is occasionally used to straighten the tortuous coronary arteries in order to achieve better accessi- bility to the distal target lesion and to avoid stent displacement from the balloon [6]. The coronary artery elongation however may induce angiographic defects"web-like" eccentric constrictions-attributed to accordion phenomenon [7]. The latter can be inappropriately identified as coronary spasm, dissection or thrombus development, which may falsely lead to unnecessary stenting at the pseudo-narrowing lesion, turning a totally reversible event into a true iatrogenic complication [6]. Vasospasm is responsive to intracoronary vasodilators like nitroglycerin (100-200 $\mu \mathrm{g})$ or calcium channel blockers. On the contrary it is well documented that vasodilators are ineffective in relieving pseudolesions and the only therapeutic management is to remove the angioplasty guide wire [8]. Intravascular ultrasound imaging may be helpful in this 


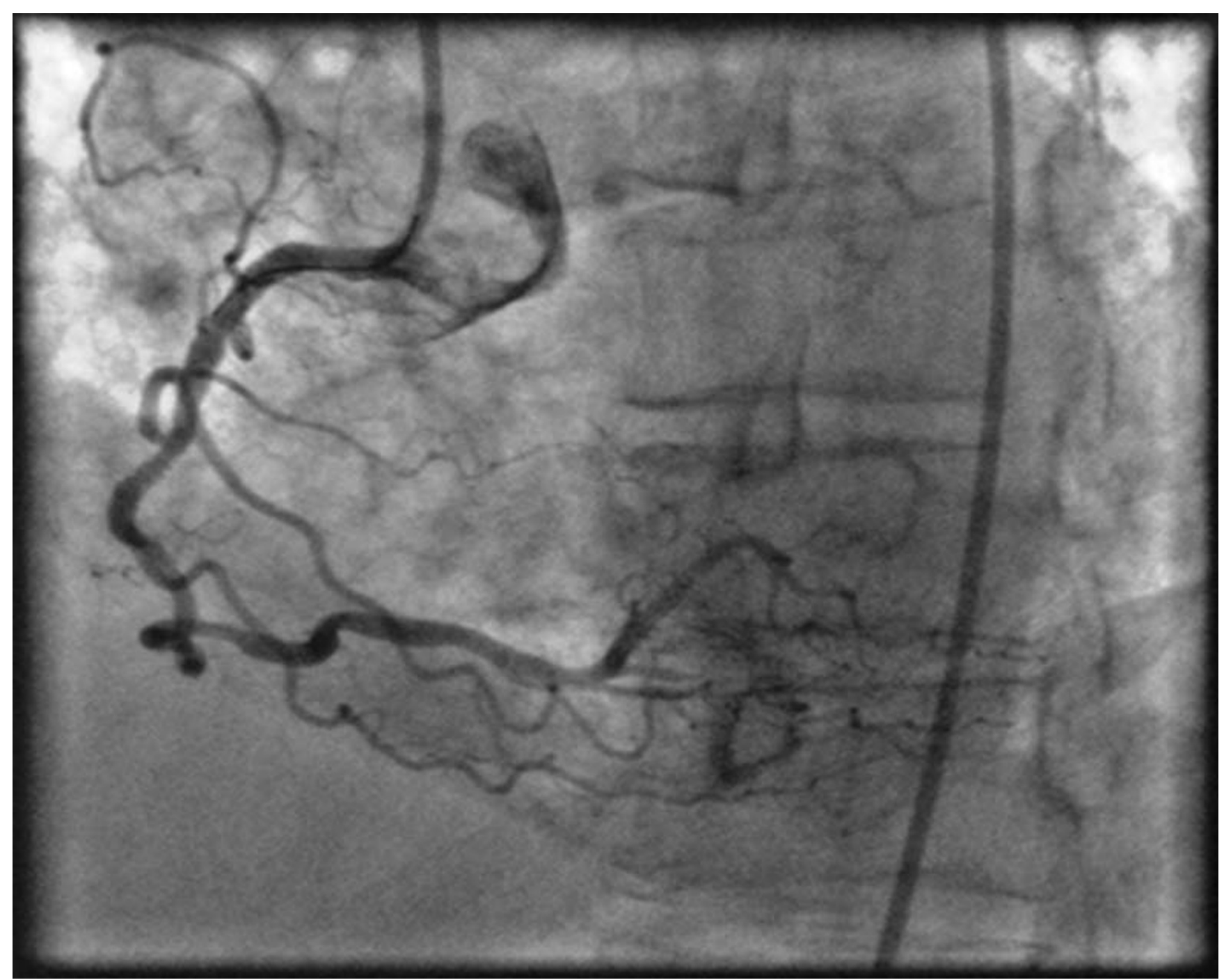

Figure 3

Final coronary angiogram after removing the guidewire showing the disappearance of focal stenoses at both stents edges. The restoration of proximal and mid segmental tortuosity resolved completely the newly developed lesions.

occasion to rule out dissection or thrombus existence prior to guide-wire removal [9].

Angioplasty with stenting on tortuous coronary arteries considered being difficult, due to hard stent delivery and possible displacement from proper position [8]. Even though, we encountered only a little resistance through stent deployment. Post-dilatation provided two new stenoses at edges of both stents. The recognition of the prestenting effect correctly certified the operators that this was a reversible phenomenon. Stiff guide wire withdrawal, facilitated the artery to restore its normal shape, with consequent disappearance of the pseudolesions and anginal symptoms.

\section{Conclusion}

Even if accordion phenomenon is predictable in tortuous coronary arteries, in the presence of stenotic lesions, it can cause reversible narrowing and transient transmural myocardial ischemia. It is essential for interventional cardiologists to identify such iatrogenic events because they are basically benign and should be managed plainly by pulling outing the guidewire and re-establishing coronary geometry.

\section{Competing interests}

The authors declare that they have no competing interests.

\section{Authors' contributions}

GG conceived the case report. GG and LKP were involved in the case management, and drafted the manuscript. PA 
and AS performed the percutaneous coronary intervention and reviewed the draft manuscript and suggested revisions. GI and IA reviewed the manuscript and made the final corrections before submission. All the authors have read and approved the final manuscript.

\section{Consent}

Written informed consent was obtained from the patient for publication of this case report and any accompanying images. A copy of the written consent is available for review by the Editor in-Chief of this journal.

\section{References}

I. Alvarez JA, Leiva G, Manavella B, Cosentino JJ: Left main crumpling during left anterior descending angioplasty: hitherto unreported location for the "accordion effect". Catheter Cardiovasc Interv 200I, 52:363-367.

2. Tsutsumi M, Kazekawa $\mathrm{K}$, Onizuka M, Aikawa $\mathrm{H}$, lko M, Kodama $\mathrm{T}$, Nii K, Matsubara S, Etou $\mathrm{H}$, Tanaka A: Accordion effect during carotid artery stenting: report of two cases and review of the literature. Neuroradiology 2007, 49(7):567-70.

3. Kim W, Jeong MH, Lee SR, Lim SY, Hong YJ, Ahn YK, Kang JC: An accordion phenomenon developed after stenting in a patient with acute myocardial infarction. International Journal of Cardiology 2007, I I 4:e60-e62.

4. Grewe K, Presti C, Perez JA: Torsion of the internal mammary graft during PTCA: A case report. Cathet Cardiovasc Diagn 1990, 19:195-19.

5. Dawson DL, Hellinger JC, Terramani TT, Najibi S, Martin LG, Lumsden LB: Iliac Artery Kinking with Endovascular Therapies: Technical Considerations. J Vasc Interv Radiol 2002, 13:729-733.

6. Asakura $Y$, Ishikawa $S$, Asakura K, Okabe T, Kanki H, Ito S, Shibata M, Sakamoto M, Takagi S, Mitamura H, Ogawa S: Successful stenting on tortuous coronary artery with accordion phenomenon: strategy - A case report. Angiology 1999, 50:765-770.

7. Leung WH, Wong CK, Lau CP: Angiographic characteristics of pseudo-narrowings caused by mechanical deformation of tortuous coronary arteries during percutaneous transluminal coronary angioplasty. I HK Coll Cardiol 1994, 2:92-98.

8. Goel PK, Agarwal A, Kapoor A: "Concertina" Effect during Angioplasty of Tortuous Rightand Left Coronary Arteries and Importance of Using Over-the-Wire System: A Case Report. Indian Heart Journal 200I, 53:87-90.

9. Alfonso F, Delgado A, Magalhaes D, Goicolea J, Hernández R, Fernández-Ortíz A, Escaned J, Banuelos C, Cortés J, Flores A, Macaya C Value of intravascular ultrasound in the assessment of psedostenosis during coronary interventions. Cathet Cardiovasc Interv 1999, 46:327.
Publish with Bio Med Central and every scientist can read your work free of charge

"BioMed Central will be the most significant development for disseminating the results of biomedical research in our lifetime. "

Sir Paul Nurse, Cancer Research UK

Your research papers will be:

- available free of charge to the entire biomedical community

- peer reviewed and published immediately upon acceptance

- cited in PubMed and archived on PubMed Central

- yours - you keep the copyright
BioMedcentral 